\title{
How Firms Go Digital? The Digital Transformation Path Analysis_ _ Evidence from Nike
}

\author{
Jiaying $\mathrm{Liu}^{1, \dagger}$, Yiran $\mathrm{Liu}^{2, \dagger}$ and Qimao Zhang ${ }^{3, *, \dagger}$ \\ ${ }^{1}$ Accounting institute, Henan University of Economics and Law, 450000, Zheng zhou, China \\ ${ }^{2}$ Business Management, Dalian University of Technology, 116024, Dalian, China \\ ${ }^{3}$ Accounting institute, Southwestern University of Finance and Economics, 401120, Chongqing, China \\ * Corresponding author: guanghua.ren@gecacademy.cn \\ tThese authors contributed equally.
}

\begin{abstract}
The digital transformation allows firms to break up traditional constraints and add value to firms in multiple ways. Many firms are using digital technologies to transform their way of doing business and further enhance their core competitiveness. Among them, Nike is an excellent digital transformer. Therefore, we use a digital transformation framework to explore how Nike goes digital successfully. This research has implications for those companies which are endeavored to looking for ways to implement digital transformation.
\end{abstract}

Keywords: Digital transformation, Digital technology, Nike, Transformation path.

\section{INTRODUCTION}

In the past 10 years, considerable attention has been paid to the innovation of many large enterprises' traditional and conventional models. Among them, digital transformation (hereafter DT) has attracted extensive interest because of the technical revolution, efficiency improvement, and unprecedented change. At a high level, DT creates a tremendous value with its peculiarity for the enterprises. In the meantime, DT also profoundly influences society and industries to the profound changes. For instance, Nike, a sports company, has increased sales from $\$ 17.29$ billion to $\$ 38.01$ billion during FY2016-2019. And the proportion is from $22 \%$ to $32.3 \%$. And the E-commerce business increase by $42 \%$ in the first quarter of FY2020, among which mobile terminal sales and APP sales contributed the most.

We choose Nike as an outstanding case to analyze for the following reasons. First, Nike has made a series of DT with its long-term vision and achieved good results in recent years. Its success in DT can be seen in its Chinese performance. In the first quarter of FY2020, Nike's e-commerce channel performance in Greater China has increased by more than $70 \%$. Second, Nike is a brand valued at nearly $\$ 35$ billion. We can see that the direct-to-consumer sales account was $33.1 \%$ of their revenues in 2020. However, ten years ago, DTC sales were only $13.5 \%$ of total Nike revenues. By emphasizing digital innovation and app downloads, Nike has steadily increased its move to e-commerce and DTC sales. The DT has become an important strategy for Nike's future development, and that why we think it is a suitable company to analyze.

Table 1.Global revenues of Nike in 2020(From the company's annual report)

\begin{tabular}{|c|c|c|c|}
\hline & \multicolumn{3}{|c|}{ YEAR ENDED MAY 31 } \\
\hline $\begin{array}{c}\text { (Dollars in } \\
\text { millions) }\end{array}$ & 2020 & 2019 & 2018 \\
\hline REVENUES & \multicolumn{3}{|c|}{} \\
\hline North American & $\$ 14484$ & $\$ 15902$ & $\$ 14855$ \\
\hline $\begin{array}{c}\text { Europe, Middle } \\
\text { East \& Africa }\end{array}$ & 9347 & 9812 & 9242 \\
\hline $\begin{array}{c}\text { Greater China } \\
\text { Asia Pacific \& } \\
\text { Latin America }\end{array}$ & 5028 & 5254 & 5166 \\
\hline $\begin{array}{c}\text { Global Brand } \\
\text { Divisions }\end{array}$ & 30 & 42 & 88 \\
\hline
\end{tabular}




\begin{tabular}{|c|c|c|c|}
\hline $\begin{array}{c}\text { Total NIKE } \\
\text { Brand }\end{array}$ & 35568 & 37218 & 34485 \\
\hline
\end{tabular}

Therefore, if we want to analyze DT's influence on an enterprise, we can focus on the definite of the DT firstly. We found many sources and analyzed those definitions, and then we arrived at a conclusion. And these three aspects will form a cycle and then be constantly updated and improved. And we will analyze based on the Nike, Inc.

\section{THEORETICAL BACKGROUND}

\subsection{Digital transformation}

Before we start to analyze the influence of the DT, we first see the definition about the digital enterprise. The obviously different between traditional and digital enterprise is the use of data. the traditional enterprise obtains the consumer's favor or data by offline store or the questionnaire. But the digital enterprise could obtain data by the online store directly or use the member registration to accumulate the consumer's data and favor. Through this way, the enterprise could analysis the consumer's favorable effective and resultful, so many traditional enterprises begin to digital transformation.

According to a review by Via 1 [1], he summarized digital transformation studies. In this review, there are three observations, first, the happening of DT is based on the organization, second, the definition about the DT has many different, third, although there are many differences, they have some similarities consist in. And there found three characters in these literature. First character is that transformation should happens in an organization. Second, it need use the digital technologies [2]. Third is that these digital technologies will creates value for the company. DT is an organizational strategy which formulate and implement some new change and then creates differentiation advantage through the using of digital technology.

\subsection{Transformation background}

\subsubsection{The industry continues to grow rapidly,} and the growth rate of sports shoes is fast.

In recent years, under the background of consumption upgrading, with the continuous popularization of sports infrastructure and health concepts, consumers' demand for sports shoes and clothing increases. The introduction of the fashion trend has successfully broken the traditional functional boundary, sports shoes and clothing gradually infiltrate into the daily life of consumers, replacing some leisure shoes and clothing, and the demand has increased greatly. In 2019, the domestic sports shoes and clothing market scale was 316.6 billion yuan, and the CAGR of the industry in the past five years was $16.4 \%$, far higher than the overall growth rate of the clothing industry in the same period ("Euromonitor International", 2019).

China's sports market is constantly expanding, which means that Nike needs to adopt a transformation strategy in this context to occupy a larger market share.

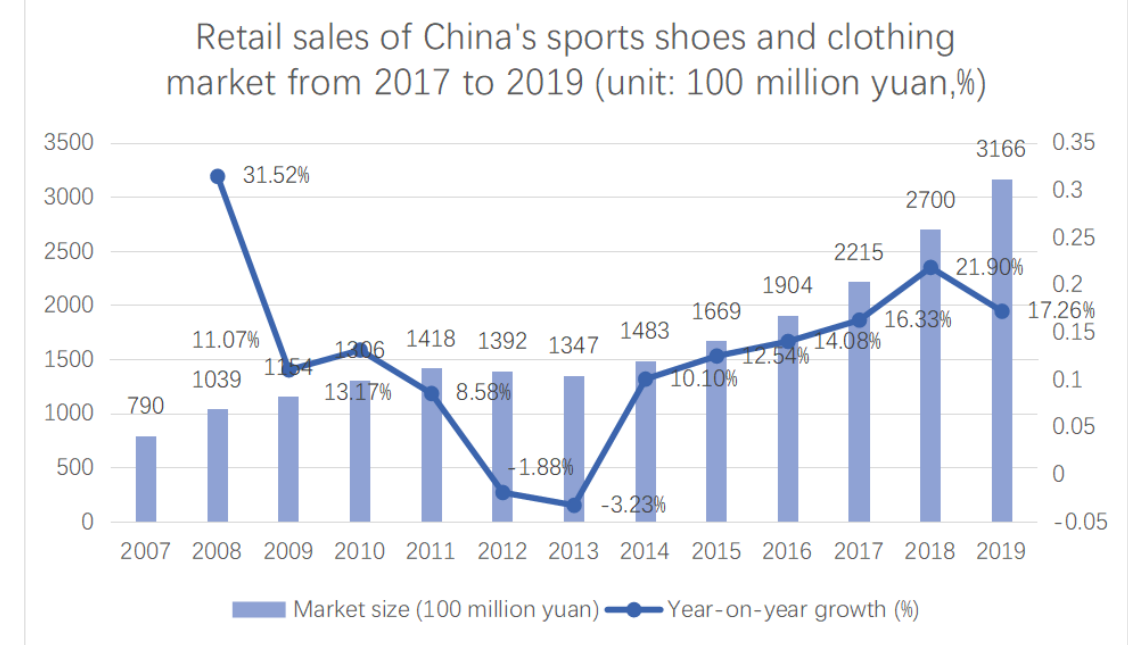

Figure 1. Retail sales of China's sports shoes and clothing market

\subsubsection{China's clothing and footwear market has a huge scale.}

From 2015 to 2019, the scale of clothing and footwear markets in the world and China showed an upward trend year by year, but in 2020, due to the COVID-19 epidemic, people's consumer confidence declined, resulting in a downward trend in the scale of clothing and footwear markets in both the world and China; However, from the perspective of the proportion of China's clothing and footwear market in the world, the proportion of China's clothing and footwear market in the global footwear market increased year by year from 2015 to 2020. Even during the COVID-19 outbreak in 2020, the proportion of China's clothing and footwear market 
in the global clothing and footwear market increased by 2.43 percentage points compared with that in 2019 .

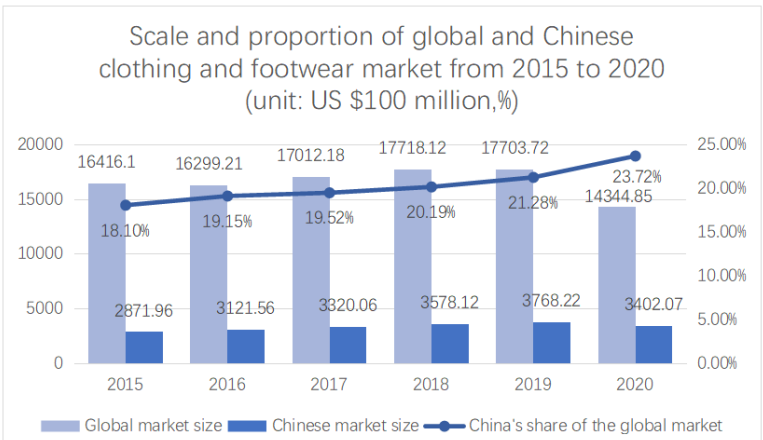

Figure 2. Scale and proportion of global and Chinese clothing and footwear market

\subsubsection{Nike's market share in China has increased year by year.}

From 2017 to 2020, Nike's operating income fluctuated and declined. In 2020, Nike's operating income was US\$ 32.376 billion, down $5.75 \%$ from 2019 . Although Nike's operating income has declined, its revenue share in Greater China is increasing year by year. In 2020, Nike's operating income in Greater China accounted for $19.00 \%$, an increase of 8 percentage points over 2017.

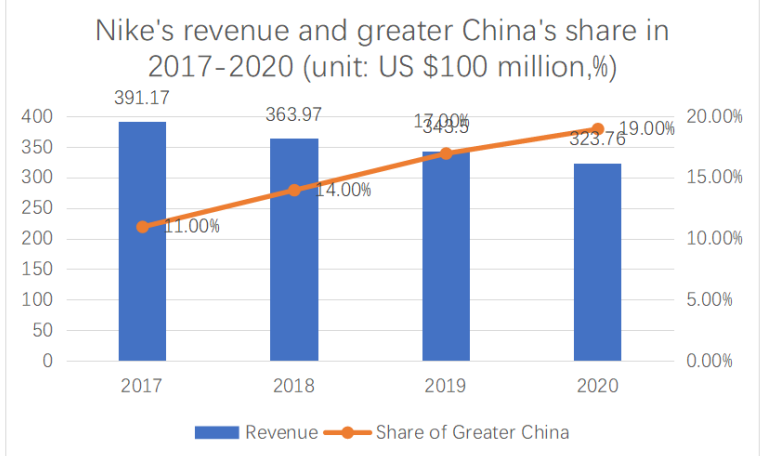

Figure 3. Nike's revenue and greater China's share

\subsubsection{The head brand accelerates the promotion} of share, and the stronger the strong the trend is obvious.
Euromonitor data shows that in 2010-2019, China's sports shoes and clothing market CR5 will rise from $51 \%$ to $72.8 \%$, and CR10 will rise from $72.2 \%$ to $86.2 \%$. Market share is concentrated in a few large enterprises such as Nike, Adidas, Anta and other industry giants. With the continuous improvement of industry concentration, resources are moving closer to the head enterprises, and the industry will present the Matthew effect of "the stronger the strong, the weaker the weak" in the future.

Market concentration of China's sports shoes and clothing industry from 2010 to 2019 (unit:\%)

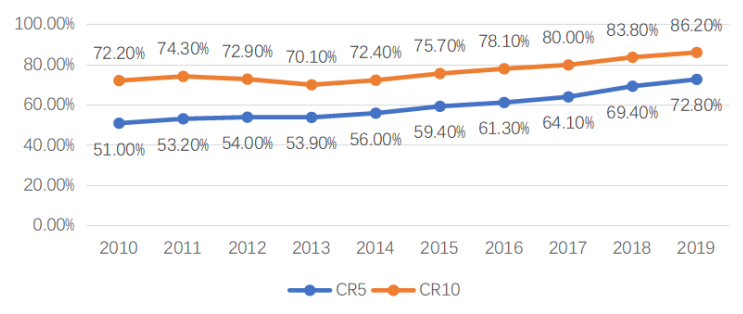

Figure 4. Market concentration of China's sports shoes and clothing industry

\subsection{Digital transformation: an inductive framework}

We present our inductive framework in Fig.5 and the following chapters, summarizing the current knowledge about DT. This framework is based on the relationships that emerge from our analysis of the nine main building blocks that describe DT as a process. DT plays a central role in creating and strengthening the disruption that occurs in society and the economy at the industry level. These interruptions trigger the strategic response of organizations, which occupy a central position in DT. Organizations use digital technologies to change the value creation path they used to rely on to remain competitive. To this end, they must implement structural changes and overcome the obstacles that hinder their transformation efforts. These changes will have a positive impact on the organization and, in some cases, on individuals and society, although they may also be positive and associated with adverse outcomes.

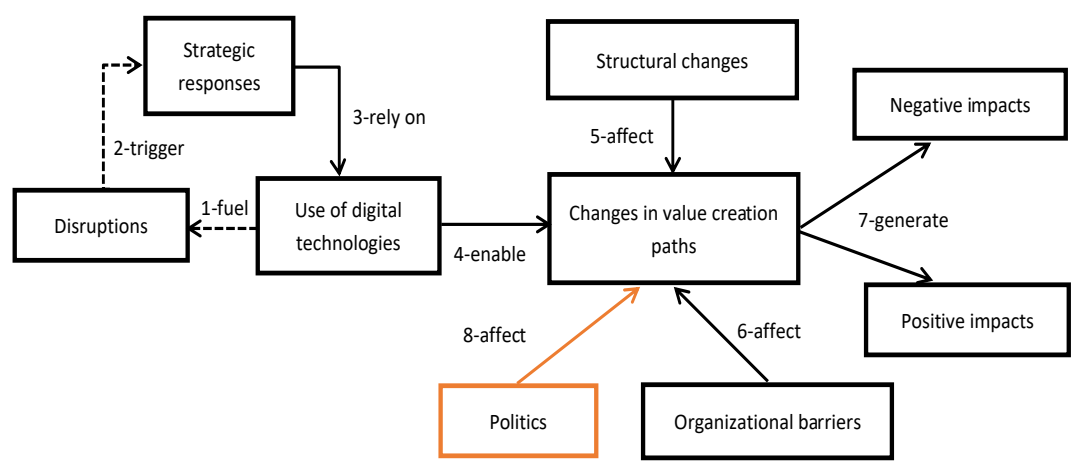

Figure 5. The framework of the DT process 


\section{DT PROCESS OF NIKE}

\subsection{Use of digital technologies}

Digital technologies are related to many aspects, such as mobile [3], analysis [4] and the most important, platforms[5]. We found that the new digital technologies not only could support consumers to meet their own demand better but also let them create greater value for other consumers [6].

Compared to the traditional clothing industries, Nile can use the data more efficiently and conveniently. Not only because it turns to digital transformation earlier, but also that it has purchased some companies in related fields to analyze data more professionally. Nike used digital technology to transform in the following ways: First, in 2016, Nike has an acquisition about digital design studio Virgin Mega to help it to develop its commercial footwear platform, SNKRS. The second, in 2018, Nike has an acquisition about Zodiac, a data analysis company, and Select, an AI analysis company. Both of these companies help Nike to strengthen the analysis of consumer data. Therefore, Nike can predict consumer's preferences for product styles, purchase time and the purchase channels more accurately. Third in 2019, Nike has an acquisition about computer vision company Invertex and launched the app 'Nike Fit mobile', which uses 3D foot scans to suggest shoe sizes to consumers more precisely, and good for reducing the number of returns and exchanges caused by mismatched shoes in online channels. Through the development of these digital technologies, Nike has greatly enhanced the capability to analyze user's data.

Nike obtains digital data and information through Nike app and e-commerce platform to grasp the consumer's demand. In the continuous process of digital transformation, we believed that Great China is the best case. This is thanks to that the digital online stores that have been completely finished in china which include the
Tmall flagship store, the official WeChat applet, NIKE.com, SNKRS App, and NIKE app. And each platform has its uniqueness, and consumers can buy the things he wants to buy in them. And those platforms create a good ecosystem that the Nike company could collects the consumers data at a high limit and those data could analysis the preferences of consumers effectively, and then give them a general direction for future designs and sales.

\subsection{Disruptions}

The literature thought that the DT has the disruptive on three aspects [7], which means that DT is an act of interrupting the continuities and changed the development.

We thought that the use of digital technologies fuels the development and brings about disruption to all the industry through three aspects. These technologies decrease the entrance barriers to a new industry and let the conventional company has a chance to generate new forms. We could understand this theory more readily by Nike's case. This company expands its business from the traditional clothes industry to e-commerce. This switch has been successfully adapted to the development of the times.

The first disruption is that it changed consumer behavior and it moved consumers' expectations higher. The rapid growth of online shopping comes into being along with the emergence of technologies. Various forms could be chosen depending on the consumers' style, and more and more consumers choose to direct online orders instead of going to the shopping mall. And this change made for Nike to collect more data and further could analysis those consumers' reference. Moreover, the company enables to grasp consumers' demand more accurately, changes to respond to consumer trends quickly, and then brings high-quality products and brand experience to the users. This picture reflects that the sales from e-commerce have gradually increased

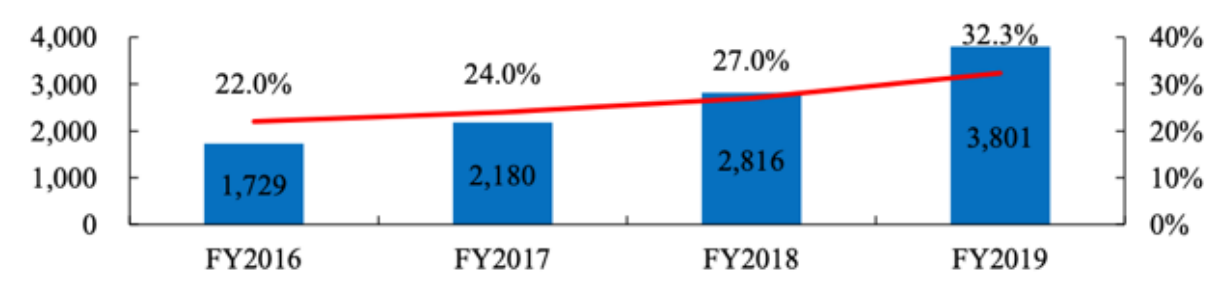

Figure 6. The proportion of online purchases to total sales of Nike

The second disruption is the competitive landscape. On Black Friday (November 30, 2019, when the Dow dropped more than 100 points), Walmart surpassed Amazon as the most downloaded APP in the US. That is to say, the digitization of the real economy has changed the current e-commerce competition pattern. The integration of online and offline can make the real economy competitive again. And for Nike, The rapid 
development of e-commerce channels has become an important driving force for the growth of Nike's direct sales. And the market shares are also stable at the first palace compared with other sports brands.

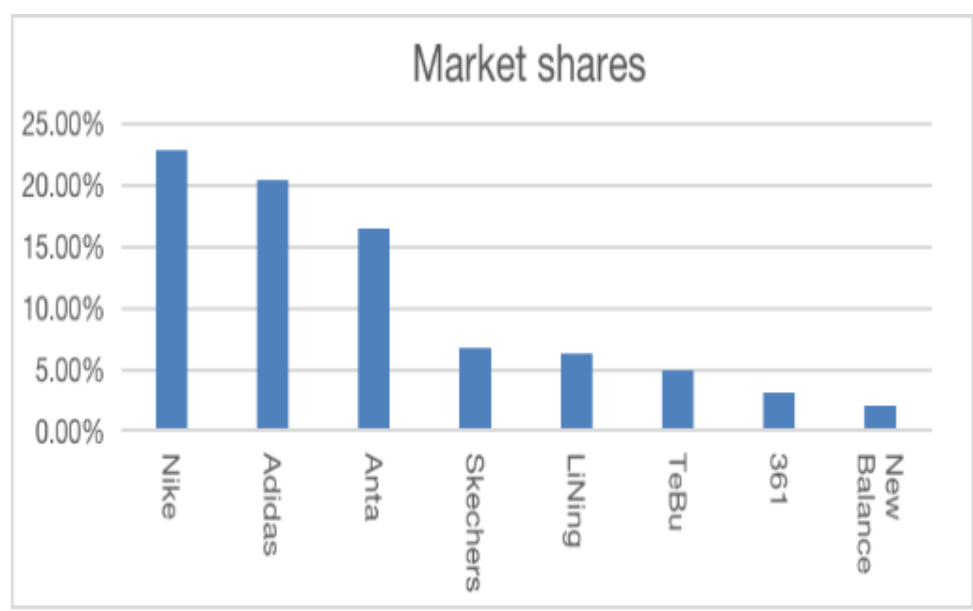

Figure 7. Market share of Chinese sports brands in 2020

The third disruption is the increasing availability of data. Just as we have analyzed above, DT has the ability to analyze data more efficiently than before, and through this way, the company could use this data to design more favorable products to attract consumers. The data which the company owns is wealth and can be used to create wealth.

\subsection{Strategic responses}

These disruptions bring opportunities as well as threats, and they are the trigger that the company begins to find the strategy. In recent industry, the company must find a way to transform to the digital and then could have a bright future. Nike caught the opportunity and made a series of strategic shifts. As mentioned above, Nike made a series of strategies about making better use of digitization are put forward, and a multi-faceted contact digital ecosystem is established to help enterprises make better use and analysis. With the help of this strategy, Nike should be able to move towards a better future.

\subsection{Transforming the value creation process}

The literature highlights the change and redefinition of business models [8] in the context of DT [9]. In this section, we describe in detail three outstanding changes and dual dexterity related to (1) value proposition, (2) value network, (3) digital channel.

Value propositions. Digital technology can create new value propositions that are increasingly dependent on the provision of services. Organizations use digital technology to transition from or increase the sales of physical products, regard service sales as an integral part of their value proposition, meet customers' needs by providing innovative solutions and collect data on their interaction with products and services [10]. Nike's mission is what drives them to do everything possible to expand human potential. They do that by creating groundbreaking sport innovations, making their products more sustainably, building a creative and diverse global team, and making a positive impact in communities where we live and work (“About Nike," 2021).

Digital channels. Organizations use digital technology to change their work distribution and sales channels. For example, in the fiscal year 2019, Nike's digital commerce sales grew $35 \%$. This momentum continued in the fiscal year 2020 as well with digital sales increasing $47 \%$ fueled by double-digit growth across all geographies. In the fourth quarter of 2020, Nike had to close $90 \%$ of its stores for around 8 weeks due to the health crisis. During this period, digital sales rose $75 \%$, making up around $30 \%$ of total revenue. Here too the lockdown pushed more people to shop online. Nike had previously aimed to reach $30 \%$ digital penetration by fiscal year 2023 but in the light of its current performance, the company believes it can reach this mark this coming year which would be over two years ahead of plan. Looking ahead, Nike expects its overall business to reach $50 \%$ digital penetration.

Value networks. Digital technology has also redefined value networks [11]. It is believed that companies can use digital technology to achieve one of the three main mediation strategies. In the disintermediation strategy, digital technology bypasses the intermediary and realizes the direct exchange between value network participants, for example, by using a platform to coordinate transactions within the supply chain [12]. When Nike app goes online, it becomes the world's largest sports brand's own online sales platform. It is at the forefront of all sports brands, deploying the core node of group data in advance for the realization of big data prediction in the future. It has become a super platform. China's consumer market is huge and digital consumption is very developed. The launch of the Nike app makes it possible for Nike to 
establish a 1:1 deep membership relationship with consumers and provide personalized services.

\subsection{Structural changes required for changing the value creation process}

Like any other program that has the potential to profoundly change the organizational structure, DT is associated with many important structural changes.

Organizational structure. One way to achieve this goal is to create an independent unit and maintain a certain degree of independence [13]. Through this structure, the unit can maintain the utilization of existing resources. At the same time, it has a relative degree of flexibility, which is conducive to innovation. Digital sports has officially become the strategic development direction of Nike. Founded in 2010, Nike Digital Sports has a team of 240 people. The most famous product is Nike + , which belongs to the same level as Nike's R \& D and marketing departments. It is in a high position in the global organizational framework of Nike. The project operation of Nike + is mainly completed by the digital marketing team responsible for running under Nike marketing department.

Leadership. In the context of DT, organizational leaders must strive to ensure that their organizations form digital thinking and are able to cope with interruptions associated with the use of digital technology [14]. Therefore, the literature emphasizes the creation of new leadership roles [15]. Around 2012, Nike implemented a large-scale DTC strategy and carried out digital transformation. In this process, the board of directors of Nike group also carried out a certain degree of "exchange of blood". Executives from GE, IBM, Microsoft, Deloitte and other technology companies have joined the board of directors of Nike, including Apple CEO Tim Cook, who joined in 2016. Donahoe, then CEO of eBay group, also became an independent director of Nike in this context. According to Nike's financial report in Fiscal Year 2019 in addition to the three senior executives with permanent positions in the company, more than half of the remaining 12 independent directors have a technology background, including two women. This reflects Nike's desire to shift from product innovation to digital technology.

\subsection{Structural changes required for changing the value creation process}

Despite these changes, inertia and resistance will still hinder the development of DT, which is consistent with the literature on it supported the organizational change.

Inertia. One of the most important obstacles to DT is inertia (35 sources). Inertia is related to the fact that existing resources and capabilities may become obstacles to interference [16], emphasizing the relevance of path dependence as a constraint force of digital technology innovation [17]. For example, Nike is deeply rooted in its existing relationships with customers and suppliers, and has complete production processes, which are highly optimized but often rigid [18], and relies on resources that are not easy to reconfigure.

\subsection{Political environment}

The change of political environment, especially the unfavorable political environment, will have a negative impact on the firm performance. Multinational firms have to face the increasing threat of opportunistic expropriation by the government as political hazards increase. Therefore, enterprises need to reasonably avoid such risks as mentioned and then get the maximum benefits.

For instance, by the end of March, 2021. the incidence of Xinjiang cotton set off a storm to garment industry. Nike announced a boycott of the cotton from Xinjiang province in China, which has prompted a large number of Chinese consumers to boycott products of Nike. For Nike, a big transcontinental enterprise, what it must to do is mitigating the political risks to avoid being used by the government for political attacks.

\subsection{Positive impacts}

In terms of organizational performance, DT has something to with value increases in several aspects. According to Vial (2019), DT can increase value in innovativeness[19], financial performance[7], firm growth [20], reputation [18] as well as a competitive advantage [21]. For NIKE, DT create value in the above ways as well.

Innovativeness. In the progress of Nike's DT, the whole industry experienced an innovation revolution at the meant time. Nike has updated its analytical technology, the ability of data collection and other aspects through the acquisition of Zodiac, Celect, Virgin Mega, and other digital technology firms. So that Nike can accurately target their customers' preferences. For instance, SNKRS was an app offered by Nike in 2015 , which will remind users when the exclusive products are available and recommend to them the products they prefer.

Financial performance. The data from Nike's annual report shows good tendency.

Table 2. The data of ROA of Nike from 2018 to 2020.

\begin{tabular}{|c|c|c|c|}
\hline & 2018 & 2019 & 2020 \\
\hline $\begin{array}{c}\text { Profit Margin } \\
\text { for ROA }\end{array}$ & $5.3 \%$ & $10.3 \%$ & $6.8 \%$ \\
\hline
\end{tabular}


Table 3. Gross profit of Nike from 2018 to 2020 (From the company's annual report)

\begin{tabular}{|c|c|c|c|}
\hline \multirow{2}{*}{} & \multicolumn{3}{|c|}{ YEAR ENDED MAY 31 } \\
\cline { 2 - 4 } & 2020 & 2019 & 2018 \\
\hline Gross profit & 16241 & 17474 & 15956 \\
\hline
\end{tabular}

Firm growth. Under the pressure that most of the people in many countries choose to avoid the epidemic at home, Nike's sales in offline stores have taken a significant hit by COVID-19, which made Nike suffer a great loss. So DT is essential in this way. From the full fiscal year of 2020, Nike's digital business has grown $49 \%$ year-over-year, with double-digit digital growth in every region. In the case of Great China, Nike's online sales have soared through the partnership with Tmall.

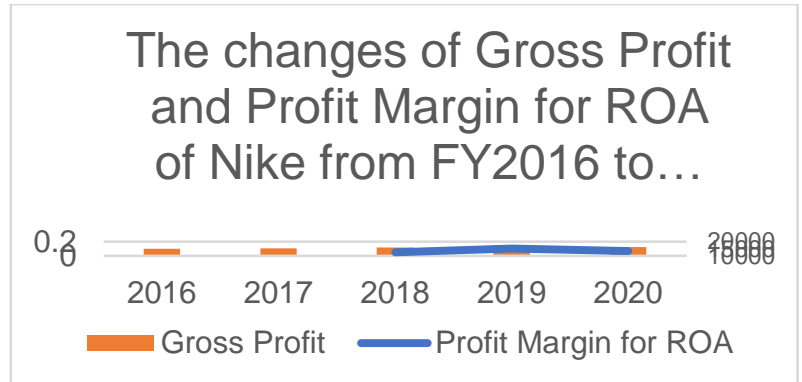

Figure 8. The changes of Gross Profit and Margin for ROA of Nike from FY2016 to FY2020

Reputation. According to the two aspects of consumer reputation and market assessments, Nike has done a good job.

Competitive advantage. Through the analysis above, it is found that Nike's digital capabilities are constantly improving, so that Nike's competitive advantage is obviously bigger compared with other enterprises in the same industry.

\section{DISCUSSION}

Through the case of Nike, we found that Nike considers the digitization as a strategic step of their path of development. Nike relies on the effective use of digital technology, which makes Nike realize the digital transformation successfully. For instance, they carried off mergers and acquisitions of other enterprises and worked with other companies (Virgin Mega, Zodiac, Celect, invertex etc.) taking digital strategy. This kind of transformation not only creates value for the corporate performance, but it also creates value for the users' experience of consumers.

Although Nike is impacted by the inertia that Nike has highly optimized but rigid and complete production process [22], and rely on resources that aren't easy to reconfigure, Nike has minor resistance in this aspect of inertia, which has accelerated the process of digital transformation.

We also found that multinational corporations should also pay much attention to the political or institutional environment. There are huge risks and even crushing blows. For instance, the fruits of the digital transformation can be stolen by the influence of the political environment.

\section{CONCLUSION}

First, future research can be conducted depending on the different characteristics of the enterprises, based on the proposed research framework above. The degree and path of DT vary from industry. The DT may occur in the production process for traditional manufacturing industry. Nevertheless, for retail industry DT may occur in the sales process.

Second, studies of multiple cases can be carried out. According to the cases of more enterprises, more derivative and general theories would be derived focusing on a number of cases.

Third, we should carry out detailed research on specific digital transformation, for we're now dealing with specific digital technologies. For Nike, data analysis is of the essence to strengthen the analysis of consumer data. Therefore, Nike can predict consumer's preferences for product styles, purchasing time and the purchasing channels more accurately.

Fourth, Nike should pay more attention to the individuation and take advantage of the existing technologies and resources to give customers a better shopping experience. For instance, with the assistance of big data, Nike could easily know the current fashion trend and give advice to consumers' looks.

\section{REFERENCES}

About Nike. (2021). Retrieved from https://www.nike.com.

[1] Vial, G., Journal of Strategic Information Systems 28 (2019) 118-144.

[2] Horlacher, A., Klarner, P., Hess, T., 2016. Crossing boundaries: organization design parameters surrounding CDOs and their digital transformation activities. In: Americas Conference of Information Systems, San Diego, CA. Westerman, G., Calméjane, C., Bonnet, D., Ferraris, P., McAfee, A. 2011. Digital transformation: a roadmap for billion-dollar organizations. In: MIT Center for Digital Business and Capgemini Consulting, pp. 1-68.

[3] Hanelt, A., Nastjuk, I., Krüp, H., Eisel, M., Ebermann, C., Brauer, B., Piccinini, E., Hildebrandt, B., and Kolbe, L. M., 2015a. Disruption on the way? The role of mobile applications for electric vehicle diffffusion. In: Wirtschaftsinformatik Conference, Osnabruck, Germany, pp. 1023-1037.

[4] Duerr, S., Wagner, H.-T., Weitzel, T., Beimborn, D., 2017. Navigating digital innovation - the 
complementary efffect of organizational and knowledge recombination. In: Wirtschaftsinformatik Conference, St. Gallen, Switzerland: AIS Electronic Library, pp. 1363-1377.

[5] Tan, B., Pan, S.L., Lu, X., Huang, L., 2015a. The role of IS capabilities in the development of multi-sided platforms: the digital ecosystem strategy of Alibaba.com. J. Assoc. Inform. Syst. 16 (4), 248. Tiwana, A., Konsynski, B., Bush, A.A., 2010. Research commentary - platform evolution: coevolution of platform architecture, governance, and environmental dynamics. Inform. Syst. Res. 21 (4), 675-687.

[6] Benedict,D. and Dellaert,C.,2019,"'The Consumer Production Journey: Marketing to Consumers as Co-producers in the Sharing Economy",Journal of the Academy of Marketing Science, 47, pp.238 254.

[7] Karimi, J., Walter, Z., 2015. The role of dynamic capabilities in responding to digital disruption: a factor-based study of the newspaper industry. J. Manage. Inform. Syst. 32 (1), 39-81.

[8] Osterwalder, A., Pigneur, Y., 2010. Business Model Generation: A Handbook for Visionaries, Game Changers, and Challengers. John Wiley \& Sons, Hoboken, New Jersey.

[9] Morakanyane, R., Grace, A.A., O'Reilly, P., 2017. Conceptualizing digital transformation in business organizations: a systematic review of literature. In: Bled eConference, Bled, Slovenia, pp. 427-444. Piccinini, E., Hanelt, A., Gregory, R., Kolbe, L., 2015b. Transforming industrial business: the impact of digital transformation on automotive organizations. In: International Conference of Information Systems, Forth Worth, TX.

[10]Porter, M.E., Heppelmann, J.E., 2014. How smart, connected products are transforming competition. Harvard Bus. Rev. 92 (11), 64-88. Wulf, J., Mettler, T., Brenner, W., 2017. Using a digital services capability model to assess readiness for the digital consumer. MIS Quart. Exec. 16 (3), 171-195.

[11]Delmond, M.-H., Coelho, F., Keravel, A., Mahl, R., 2017. How information systems enable digital transformation: a focus on business models and value co-production. IUP J. Bus. Strat. 14 (3), 7-40.

[12]Klötzer, C., Pflaum, A., 2017. Toward the development of a maturity model for digitalization within the manufacturing industry's supply chain. In: Hawaii International Conference on System Sciences, Waikoloa Beach, HI, pp. 4210-4219.

[13] Maedche, A., 2016. Interview with michael nilles on "What Makes Leaders Successful in the Age of the
Digital Transformation?". Bus. Inform. Syst. Eng. 58 (4),287-289.

[14]Benlian, A., Haffke, I., 2016. Does mutuality matter? Examining the bilateral nature and effects of CEO-CIO mutual understanding. J. Strat. Inform. Syst. 25 (2),104-126.

[15]Haffke, I., Kalgovas, B.J., Benlian, A., 2016. The role of the CIO and the CDO in an organization's digital transformation. In: International Conference of Information Systems, Dublin, Ireland.

[16]Islam, N., Buxman, P., Eling, N., 2017. Why should incumbent firms jump on the start-up bandwagon in the digital era? A qualitative study. In: Wirtschaftsinformatik Conference, St. Gallen, Switzerland: AIS Electronic Library, pp. 13781392. Svahn, F., Mathiassen, L., Lindgren, R., 2017a. Embracing digital innovation in incumbent firms: how Volvo Cars managed competing concerns. MIS Quart. 41 (1),239-253.

[17] Srivastava, S.C., Shainesh, G., 2015. Bridging the service divide through digitally enabled service innovations: evidence from Indian health care service providers. MIS Quart. 39 (1), 245-267. Wenzel, M., Wagner, D., Wagner, H.-T., Koch, J., 2015. Digitization and path disruption: an examination in the funeral industry. In: European Conference of Information Systems, Munster, Germany.

[18]Andriole, S.J., 2017. Five myths about digital transformation. MIT Sloan Manage. Rev. 58 (3), 20-22.

[19]Svahn, F., Mathiassen, L., Lindgren, R., 2017a. Embracing digital innovation in incumbent firms: how Volvo Cars managed competing concerns. MIS Quart. 41 (1),239-253.

[20]Tumbas, S., Berente, N., Seidel, S., vom Brocke, J., 2015. The 'digital façade' of rapidly growing entrepreneurial organizations. In: International Conference of Information Systems, Forth Worth, TX.

[21]Kane, G.C., 2016c. How Facebook and Twitter are reimagining the future of customer service. MIT Sloan Manage. Rev. 55(4), 1-6.

[22]Andriole, S.J., 2017. Five myths about digital transformation. MIT Sloan Manage. Rev. 58 (3), $20-22$. 